\title{
Mania reduces perceived pain intensity in patients with chronic pain: preliminary evidence from retrospective archival data
}

This article was published in the following Dove Press journal:

Journal of Pain Research

23 March 2016

Number of times this article has been viewed

\author{
lan A Boggero' \\ Jonathan D Cole ${ }^{2}$ \\ 'Department of Psychology, University \\ of Kentucky, ${ }^{2}$ Bluegrass Health \\ Psychology, Lexington, KY, USA
}

Objective: Bipolar disorder is associated with poor pain outcomes, but the extant literature has not taken into account how mania or hypomania - a central feature of bipolar disorders influences pain intensity. The objective of this study was to describe whether patients recalled experiencing reduced pain intensity during manic or hypomanic episodes.

Design and setting: This study used a retrospective design using archival data from patient's medical records.

Subjects: A total of 201 patients with chronic pain with bipolar I (39.6\%) or bipolar II (60.4\%) disorder who were undergoing a psychological evaluation for an interventional pain procedure were included in this study.

Methods: Patients underwent a semistructured interview where they were asked if they recalled reductions in pain intensity during their most recent manic or hypomanic episode. The proportion of patients who responded "yes" versus "no" to this question was the primary outcome variable.

Results: Results reveal that $64.2 \%$ of patients recalled experiencing a reduction in pain intensity during their most recent manic or hypomanic episode.

Conclusion: Perceptions of reduced pain intensity during mania or hypomania may contribute to a cycle of increased activity during manic episodes, which may increase pain over time. It may also lead to false-positive findings on spinal cord stimulator trials and diagnostic pain blocks, among other interventional pain procedures. The preliminary findings of this study highlight the clinical importance of assessing for bipolar disorders in patients with chronic pain.

Keywords: affective disorders, bipolar disorder, pain perception, positive affect, psychopathology

\section{Introduction}

Chronic pain is defined as an unpleasant sensory and affective experience associated with actual or potential tissue damage. ${ }^{1-3}$ The affective contributions to chronic pain are evidenced by the fact that some mood disorders, most commonly depression, predict and maintain fibromyalgia, orofacial pain, and osteoarthritis, among other chronic pain disorders. ${ }^{4-7}$ The effect of depression on pain is partially due to negative affect, which in and of itself is associated with higher self-reported pain intensity. ${ }^{8}$ However, other mood disorders, such as bipolar disorders, are characterized by periods of increased energy and positive affect and may be associated with reduced pain intensity. ${ }^{9}$ The intent of this study was to describe if chronic pain patients with bipolar disorder recalled experiencing lower pain intensity during their most recent episode of mania or hypomania.
Department of Psychology, University of Kentucky, I7I Funkhouser Drive, Lexington, KY 40506, USA

$\mathrm{Tel}+\mathrm{I} 8592572207$

Fax + I 8593231979

Email ian.boggero@uky.edu 
Manic episodes are defined by distinct periods of elevated mood, decreased need for sleep, excessive involvement in pleasurable activities, and inflated self-esteem or grandiosity, among other symptoms. Hypomanic episodes are characterized by similar symptoms but are less intense and of shorter duration. Bipolar disorders are subcategorized into bipolar I if a history of depressive and manic episodes are present, or bipolar II if a history of depressive and hypomanic episodes are present (ie, no lifetime history of a full manic episode). There is wide variability, both between and within people, regarding the duration of manic or hypomanic episodes. ${ }^{10}$ Therefore, positive affect in patients with bipolar disorders may also be widely variable, depending on their current point in the bipolar cycle of depression, hypomania, or mania. This is particularly important for the assessment of pain because positive affect decreases pain intensity in patients with chronic pain. ${ }^{11-13}$

If positive affect decreases pain intensity and bipolar disorders are characterized by manic or hypomanic episodes with positive affect, then patients with bipolar disorders should report lower pain intensity on average than those with depression or other mood disorders of negative affect. Yet, the extant literature on bipolar disorder and pain suggests just the opposite. In a recent meta-analysis of 22 studies, $\sim 25 \%$ of patients with chronic pain had bipolar disorder, and those with bipolar disorder were at significant risk for experiencing clinically relevant pain (relative risk ratio $=2.14$ ) ${ }^{14}$ In a study of 157 patients with fibromyalgia, lifetime symptoms of depression and mania were similarly correlated with pain $(r=0.24$ for lifetime depression and pain, and $r=0.20$ for lifetime mania and pain).${ }^{15}$ In another study of $>800$ people with bipolar disorder, those with a manic episode in the past 12 months reported significantly higher pain interference than those with a depressive episode in the past 12 months. ${ }^{16}$ These findings suggest that a lifetime history of bipolar disorder is associated with higher, not lower, pain intensity and interference.

A major limitation with the literature on bipolar disorder and chronic pain is that the extant studies use established bipolar diagnosis but do not assess for mania or hypomania. As a result, there are no data on how pain intensity changes during a manic or hypomanic phase. In this study, we aimed to examine how mania influenced pain intensity in patients with chronic pain diagnosed with bipolar disorders. To do this, patients with chronic pain with bipolar disorders were asked to recall if they had experienced reduced pain intensity during their most recent manic or hypomanic episode. Based on the literature on positive affect and pain, it was hypothesized that patients would recall experiencing reduced pain intensity during their most recent manic or hypomanic episode. This is the first study to our knowledge that describes the associations between mania or hypomania and pain intensity. Data on pain intensity during mania may have important implications for the treatment and management of chronic pain disorders.

\section{Methods \\ Participants}

A total of 225 consecutive chronic pain patients with bipolar disorder seen at a private pain psychology clinic between April 2007 and April 2015 were included in this study. Patients were referred to a pain psychologist by their pain management specialist for a psychological evaluation for an interventional pain procedure (ie, a spinal cord stimulator) or to be put on opiate mediation. The average age of the sample group was 47.47 years (standard deviation $[\mathrm{SD}]=10.06$ years, range: $20-81$ years), and the sample was $74 \%$ female $(n=167)$. The patients in the sample were Caucasian $(n=220,97.8 \%)$ and African-American ( $\mathrm{n}=5,2.2 \%)$. Primary pain location of the sample was lumbar $(n=103,45.8 \%)$, neck $(n=41,18.2 \%)$, leg $(n=22,9.8 \%)$, thoracic $(n=16,7.1 \%)$, entire body $(n=14$, $6.2 \%)$, head $(n=11,4.9 \%)$, and other parts (including jaw, chest, and shoulder; $\mathrm{n}=18,8.0 \%$ ). Approximately $82.9 \%$ of the sample also had a second pain location, $44.0 \%$ had a third pain location, and $12.9 \%$ had a fourth pain location. The majority of the sample was previously diagnosed as having chronic lower back pain by their pain management physicians, although there were no inclusion or exclusion criteria based on primary diagnosis in this study.

With regard to psychiatric diagnosis, $60.4 \%$ of the sample had a primary diagnosis of bipolar II and $39.6 \%$ of the sample had a primary diagnosis of bipolar I. Secondary psychiatric diagnosis included generalized anxiety disorder $(\mathrm{n}=31,13.8 \%)$, anxiety disorder not otherwise specified $(\mathrm{n}=25,11.1 \%$ ), specific phobia $(\mathrm{n}=18,8.0 \%)$, panic disorder $(\mathrm{n}=7,3.1 \%)$, and others (including posttraumatic stress disorder, substance abuse/dependence disorders, obsessive-compulsive disorder, and bulimia nervosa; $\mathrm{n}=18,8.0 \%$ ). Institutional approval and written consent was not sought as the study used deidentified data originally collected for non-research purposes.

\section{Procedures}

Patients were referred by their pain management physician to a private pain psychologist to undergo a psychological evaluation for interventional pain procedures. Upon arriving at the office, they were asked to complete medical paperwork regarding their insurance provider, their medical history, and their psychological functioning. They were then interviewed by a board-certified health psychologist for 30-45 minutes. 
All interviews were conducted by the same board-certified psychologist to improve reliability. During this semistructured interview, the psychologist asked the patient about their pain condition and had them report the duration of the pain along with the lowest, highest, and average pain intensity in the past month, using a ten-point scale with 0 being no pain and 10 being the worse pain imaginable. They were then asked about the symptoms of psychopathology, including depression, mania, and posttraumatic stress disorder. If patients endorsed symptoms of mania or hypomania, the psychologist asked them whether they noticed reductions in pain intensity during these episodes. Verbal responses to this question were coded as yes/no at the time of the interview by the interviewing psychologist. Following the interview, the psychologist made a psychological diagnosis based on Diagnostic and Statistical Manual, fourth revision criteria. Data obtained during the evaluation were scored and included in the patient's medical records. For the purpose of the study, demographic information; data of pain location, intensity, and duration; psychological diagnosis; and the response to the yes/no question of whether they had noticed that mania or hypomania reduced their pain intensity were extracted from the patient's medical records and conjugated into a deidentified database.

\section{Data analysis plan}

Data were first checked for outliers and missing values. No outliers on the relevant study variables were detected using a criterion of \pm 3 SDs. Missing data analyses revealed that one person was missing average pain intensity. This case was excluded for analyses including the average pain intensity variable. Next, descriptive statistics were computed among all study variables. $t$-Tests were conducted to test whether the bipolar I and bipolar II groups differed with regard to age; low, average, or high self-reported pain intensities; and pain duration. The primary analyses were conducted by using a chi-square test to determine if there were differences in the percentage of patients with bipolar I or II disorder who recalled experiencing decreases in pain intensity during their most recent episode of mania or hypomania. Data were analyzed using SPSS version 22 (IBM Corporation, Armonk, NY, USA).

\section{Results}

\section{Comparisons between patients with bipolar I and bipolar II disorders on demographic and pain variables}

$t$-Tests were conducted to test for demographic or pain differences among the bipolar I and II groups. Table 1 reveals that
Table I Differences between patients with bipolar I and bipolar II disorders on selected study variables

\begin{tabular}{|c|c|c|c|c|c|c|c|}
\hline Variable & $\begin{array}{l}\text { Psychological } \\
\text { diagnosis }\end{array}$ & $\mathbf{n}$ & Mean & SD & $t$ & $d f$ & $P$-value \\
\hline \multirow[t]{2}{*}{ Age, years } & Bipolar I & 89 & 49.97 & 10.08 & \multirow[t]{2}{*}{0.60} & \multirow[t]{2}{*}{223} & \multirow[t]{2}{*}{0.55} \\
\hline & Bipolar II & 136 & 47.15 & 10.07 & & & \\
\hline Pain & Bipolar I & 87 & 101.91 & 81.51 & \multirow[t]{2}{*}{-0.39} & \multirow[t]{2}{*}{213} & \multirow[t]{2}{*}{0.70} \\
\hline $\begin{array}{l}\text { duration, } \\
\text { months }\end{array}$ & Bipolar II & 128 & 106.53 & 88.86 & & & \\
\hline Average pain & Bipolar I & 88 & 6.31 & 2.31 & \multirow[t]{2}{*}{0.04} & \multirow[t]{2}{*}{222} & \multirow[t]{2}{*}{0.97} \\
\hline intensity & Bipolar II & 136 & 6.30 & 2.16 & & & \\
\hline Lowest pain & Bipolar I & 89 & 3.84 & 1.73 & \multirow[t]{2}{*}{1.04} & \multirow[t]{2}{*}{223} & \multirow[t]{2}{*}{0.30} \\
\hline intensity & Bipolar II & 136 & 3.59 & I.74 & & & \\
\hline Highest pain & Bipolar I & 89 & 9.59 & 0.87 & \multirow[t]{2}{*}{1.76} & \multirow[t]{2}{*}{223} & \multirow[t]{2}{*}{0.08} \\
\hline intensity & Bipolar II & 136 & 9.36 & 1.01 & & & \\
\hline \multirow{6}{*}{$\begin{array}{l}\text { Number of } \\
\text { days } \\
\text { since most } \\
\text { recent manic } \\
\text { or hypomanic } \\
\text { episode }\end{array}$} & Bipolar I & 77 & 328.69 & 735.31 & \multirow{6}{*}{1.23} & \multirow[t]{6}{*}{199} & \multirow[t]{6}{*}{0.22} \\
\hline & Bipolar II & 124 & 210.06 & 618.21 & & & \\
\hline & & & & & & & \\
\hline & & & & & & & \\
\hline & & & & & & & \\
\hline & & & & & & & \\
\hline
\end{tabular}

Abbreviations: $d f$, degrees of freedom; SD, standard deviation.

there were no differences in demographic or pain variables between the bipolar I and II groups.

\section{Reduced pain intensity during manic or hypomanic episodes}

A chi-square analysis was conducted to test whether patients with bipolar disorder recalled experiencing reduction in pain during their most recent episodes of mania or hypomania. For 24 people, the duration of pain was shorter than the time since the last manic or hypomanic episode. Thus, these 24 people were excluded from the analysis. Table 2 reveals that $64.2 \%$ of people with bipolar I or bipolar II disorder recalled experiencing reductions in pain intensity during manic or hypomanic episodes. Results revealed that there were no significant differences in the percentage of people

Table 2 Chi-square comparing perceived pain reduction during manic or hypomanic episode

\begin{tabular}{llll}
\hline $\begin{array}{l}\text { Psychological } \\
\text { diagnosis }\end{array}$ & Measure & \multicolumn{2}{l}{$\begin{array}{l}\text { Notice pain reduction during } \\
\text { manic/hypomanic episode? }\end{array}$} \\
\hline \multirow{3}{*}{ Bipolar I } & Count & No & Yes \\
& \% of total & $17.9 \%$ & 48 \\
Bipolar II & Count & 36 & $23.9 \%$ \\
& \% of total & $17.9 \%$ & 81 \\
Total & Count & 72 & $40.3 \%$ \\
& \% of total & $35.8 \%$ & 129 \\
& & & $64.2 \%$ \\
\hline
\end{tabular}


who recalled experiencing pain intensity reduction between patients with bipolar I and bipolar II disorders, $\chi^{2}(1, \mathrm{~N}=201)$ $=3.11, P=0.10$.

\section{Discussion}

Whereas the contributions of mood disorders to chronic pain conditions have long been explored, the majority of research has focused on depression and other mood disorders characterized by negative affect. ${ }^{17} \mathrm{~A}$ relative dearth of studies have focused on bipolar disorder, partially characterized by positive affect. The evidence that does exist suggests that bipolar disorder, much like other mood disorders, serves as a risk factor for developing chronic pain conditions and can negatively impact how people cope with and manage pain. ${ }^{14}$ Chronic pain patients with bipolar disorder report higher pain interference and pain-related distress than patients without bipolar disorder. ${ }^{16} \mathrm{~A}$ major limitation of this research has been that studies have focused on a positive history of bipolar diagnosis while ignoring how pain intensity changes during manic or hypomanic episodes.

In the first data to our knowledge to report on pain perception during mania, we found that $>64 \%$ of chronic pain patients with bipolar disorder recalled experiencing reduced pain intensity during manic or hypomanic episodes, characterized by increased energy, decreased need for sleep, and positive affect, among other symptoms. Importantly, the percentages of patients noticing this reduction were similar among patients with bipolar I and bipolar II disorders. These data can have important clinical implications. To the extent that patients perceive a reduction in pain during manic or hypomanic episodes, they may be tempted to engage in more activities than what is recommended. This lack of activity pacing may result in exacerbated pain levels in the future and may ultimately contribute to increases in pain over time. ${ }^{18-20}$ When the manic phase resolves, increases in pain may become particularly noticeable, contributing to a cycle of overactivity and pain. This cycle may explain the extant finding that patients with bipolar pain, on average, report higher pain intensity and interference than patients with pain with other mood disorders, including major depressive disorder. ${ }^{16}$

A number of studies ${ }^{11,12,13,21}$ have tested the role of positive affect in coping with pain. In one study, 124 women with osteoarthritis or fibromyalgia were tracked for up to 12 weeks, with pain and affective variables being collected at each visit. Positive affect longitudinally predicted reductions in subsequent pain-related negative affect and also predicted lower levels of pain in subsequent weeks. ${ }^{21}$ Other studies corroborate the finding that positive emotionality can help patients with chronic pain cope up with pain. ${ }^{11-13}$ This study provides further evidence to that body of literature by showing that mania, characterized by positive affect, may significantly reduce perceived pain intensity. It is likely that this occurs via the affective (versus the somatosensory) pathways of the pain system, although this should be subjected to more rigorous tests in the future. In any case, if positive affect can indeed reduce perceptions of pain, then psychological treatments for patients with chronic pain should be geared toward improving positive affect instead of merely minimizing negative affect.

Higher self-reported perceptions of pain are associated with higher likelihood of opioid use, greater pain interference, more psychological distress, and reduced daily functioning, suggesting that the way people perceive pain matters. ${ }^{3,22-25} \mathrm{To}$ the extent that mania or hypomania influences perceptions of pain, people's reports of their pain intensity, disability, and interference may be biased and inaccurate when they are in a manic or hypomanic state. This is a particularly important consideration when conducting psychological assessments for pain procedures such as spinal cord stimulators, diagnostic blocks, or steroid injections. Spinal cord stimulator surgery is preceded by a trial period. The trial is considered successful if it significantly reduces pain. If, during this trial period, a patient is in a manic or hypomanic phase and is underreporting pain, then the results of the trial may result in a false positive. ${ }^{26}$ The consequences of this are significant as it may lead to an unnecessary or unsuccessful surgery. Similarly, decreased perceptions of pain may invalidly produce false-positive results in diagnostic blocks, possibly leading to misdiagnosis and medication mismanagement. Validly assessing mania or hypomania symptoms is also important prior to recommending steroid injections as steroid injections can trigger manic episodes in some cases. ${ }^{27}$ These examples highlight the importance of assessing manic symptoms and suggest that a period of affective stability should be a necessary requirement prior to interventional pain procedures.

\section{Limitations}

This study has several significant limitations. The design of the study is retrospective in that patients were asked to recall whether they had noticed decreases in pain during their most recent manic or hypomanic episode and did not actually provide pain measures during the manic episode. If patients reported that they did not recall decreases in pain, it is unknown whether this was because there were no changes in pain, they did not notice them, or were not remembering the changes accurately. Thus, recall bias presents a significant 
limitation of this study. To overcome this limitation, patients should be brought into the laboratory before, during, and after a manic or hypomanic episode. Objective pain threshold and subjective pain tolerance testing should be conducted during these laboratory visits to determine whether there are changes in the somatosensory or affective dimensions of pain. Despite the logistic difficulty of a within-subject design in patients with bipolar disorder in a manic or hypomanic state, the information would be invaluable for informing theory and clinical management of chronic pain patients with bipolar disorder. A second major limitation of the study is that the assessment of psychopathology was conducted via a semistructured interview and was not corroborated with validated assessment instruments. A third limitation was that pain diagnosis was not included as a variable in this study. Although the relationships between mania or hypomania and perceptions of pain can be expected to be similar across diagnoses, future studies should confirm this. A fourth limitation is that the sample was primarily Caucasian and, in light of race differences in pain and pain perceptions, cannot be expected to generalize to other racial categories. ${ }^{28}$

Despite these weaknesses, this study has significant strengths. For one, it is the only study to our knowledge to attempt to examine how mania influences perceptions of pain. The fact that $>64 \%$ of patients with bipolar pain with chronic pain recalled experiencing reduced pain during mania highlights important future directions. As mentioned previously, one future direction would be to use a within-subject design to test subjective and objective measures of pain before and after a manic episode. Future research should also aim to explore factors that differentiate the $64 \%$ who did notice reductions in pain intensity from the $36 \%$ who did not. Finally, and perhaps most importantly, this study highlights the need for future research with bipolar disorder and chronic pain. Whereas much is known about depression and pain, significantly less is known about bipolar disorder and pain. Given the high prevalence of patients with pain who have bipolar disorder, greater focus should be placed on helping treat and study this population.

\section{Acknowledgments}

Research reported in this publication was supported by the National Institute on Aging of the National Institutes of Health under Award Number F31AG048692. The content is solely the responsibility of the authors and does not necessarily represent the official views of the National Institutes of Health.

\section{Disclosure}

The authors report no conflicts of interest in this work.

\section{References}

1. Price DD. Psychological and neural mechanisms of the affective dimension of pain. Science. 2000;288(5472):1769-1772.

2. Rainville P, Duncan GH, Price DD, Carrier B, Bushnell MC. Pain affect encoded in human anterior cingulate but not somatosensory cortex. Science. 1997;277(5328):968-971.

3. Boggero IA, Carlson CR. Somatosensory and affective contributions to emotional, social, and daily functioning in chronic pain patients. Pain Med. 2014;16(2):341-347.

4. Fuller-Thomson E, Nimigon-Young J, Brennenstuhl S. Individuals with fibromyalgia and depression: findings from a nationally representative Canadian survey. Rheumatol Int. 2012;32(4):853-862.

5. Sipilä K, Mäki P, Laajala A, Taanila A, Joukamaa M, Veijola J. Association of depressiveness with chronic facial pain: a longitudinal study. Acta Odontol Scand. 2013;71(3-4):644-649.

6. Hawker GA, Gignac MA, Badley E, et al. A longitudinal study to explain the pain-depression link in older adults with osteoarthritis. Arthritis Care Res (Hoboken). 2011;63(10):1382-1390.

7. Hilderink PH, Burger H, Deeg DJ, Beekman AT, Voshaar RCO. The temporal relation between pain and depression: results from the longitudinal aging study Amsterdam. Psychosom Med. 2012;74(9): 945-951.

8. Zautra AJ, Smith B, Affleck G, Tennen H. Examinations of chronic pain and affect relationships: applications of a dynamic model of affect. J Consult Clin Psychol. 2001;69(5):786-795.

9. Edge MD, Miller CJ, Muhtadie L, et al. People with bipolar I disorder report avoiding rewarding activities and dampening positive emotion. $J$ Affect Disord. 2013;146(3):407-413.

10. Angst J, Gamma A, Benazzi F, Ajdacic V, Eich D, Rössler W. Toward a re-definition of subthreshold bipolarity: epidemiology and proposed criteria for bipolar-II, minor bipolar disorders and hypomania. $J$ Affect Disord. 2003;73(1):133-146.

11. Ong AD, Zautra AJ, Reid MC. Psychological resilience predicts decreases in pain catastrophizing through positive emotions. Psychol Aging. 2010;25(3):516-523.

12. Strand EB, Zautra AJ, Thoresen M, Ødegård S, Uhlig T, Finset A. Positive affect as a factor of resilience in the pain - negative affect relationship in patients with rheumatoid arthritis. $J$ Psychosom Res. 2006;60(5):477-484.

13. Yeung EW, Arewasikporn A, Zautra AJ. Resilience and chronic pain. J Soc Clin Psychol. 2012;31(6):593-617.

14. Stubbs B, Eggermont L, Mitchell AJ, et al. The prevalence of pain in bipolar disorder: a systematic review and large-scale meta-analysis. Acta Psychiatr Scand. 2015;131(2):75-88.

15. Osso LD, Bazzichi L, Consoli G, et al. Manic spectrum symptoms are correlated to the severity of pain and the health-related quality of life in patients with fibromyalgia. Clin Exp Rheumatol. 2009;27: s57-s61.

16. Goldstein BI, Houch PR, Karp JF. Factors associated with pain interference in an epidemiologic sample of adults with bipolar I disorder. J Affect Disord. 2009;117:151-156.

17. Fishbain DA. Psychiatric pain-associated comorbidities. In: McMahon SB, Koltzenburg M, Tracey I, Turk DC, editors. Wall and Melzacks's Textbook of Pain. 6th ed. Philadelphia, PA: Elsevier; 2013:273-282.

18. Mead K, Theadom KA, Byron K, Dupont S. Pilot study of a 4-week pain coping strategies (PCS) programme for the chronic pain patient. Disabil Rehabil. 2007;29:199-203.

19. Philips HC, Rachman S. The role of activity pacing. In: Philips HC, Rachman S, editors. The Psychological Management of Chronic Pain: A Treatment Manual. New York, NY: Springer; 1996:174-184.

20. Gill JR, Brown CA. Structured review of the evidence for pacing as a chronic pain intervention. Eur J Pain. 2009;13:214-216. 
21. Zautra AJ, Johnson LM, Davis MC. Positive affect as a source of resilience for women in chronic pain. J Consult Clin Psychol. 2005;73(2):212-220.

22. VanDenKerkhof EG, Hopman WM, Goldstein DH, et al. Impact of perioperative pain intensity, pain qualities, and opioid use on chronic pain after surgery: a prospective cohort study. Reg Anesth Pain Med. 2012;37(1):19-27.

23. Bonar EE, Ilgen MA, Walton M, Bohnert AS. Associations among pain, non-medical prescription opioid use, and drug overdose history. Am J Addict. 2014;23(1):41-47.

24. Osborne TL, Jensen MP, Ehde DM, Hanley MA, Kraft G. Psychosocial factors associated with pain intensity, pain-related interference, and psychological functioning in persons with multiple sclerosis and pain. Pain. 2007;127(1):52-62.
25. Boggero IA, Kniffin TC, de Leeuw R, Carlson CR. Fatigue mediates the relationship between pain interference and distress in patients with persistent orofacial pain. J Oral Facial Pain Headache. 2013;28(1):38-45.

26. Block AR, Gatchel RJ, Deardorff WW, Guyer RD. The Psychology of Spine Surgery. Washington, DC: American Psychological Association; 2003.

27. Benyamin RM, Vallejo R, Kramer J, Rafeyan R. Corticosteroid induced psychosis in the pain management setting. Pain Physician. 2008;11(6):917-920.

28. Riley JL, Wade JB, Myers CD, Sheffield D, Papas RK, Price DD. Racial/ethnic differences in the experience of chronic pain. Pain. 2002;100(3):291-298.

\section{Publish your work in this journal}

The Journal of Pain Research is an international, peer-reviewed, open access, online journal that welcomes laboratory and clinical findings in the fields of pain research and the prevention and management of pain. Original research, reviews, symposium reports, hypothesis formation and commentaries are all considered for publication.

\section{Dovepress}

The manuscript management system is completely online and includes a very quick and fair peer-review system, which is all easy to use. Visit http://www.dovepress.com/testimonials.php to read real quotes from published authors. 